\title{
Conflict Management Style and Nurses Turnover Intention in Secondary Care Hospital Lahore
}

\author{
Roofen julious, Reg \# PBSN02163007 \\ Lahore School of Nursing \\ The University of Lahore \\ Lahore, Pakistan \\ Muhammad Afzal, associate professor \\ Lahore School of Nursing \\ The University of Lahore \\ Lahore, Pakistan \\ Muhammad Hussain, Assistant Professor \\ Lahore School of Nursing \\ The University of Lahore \\ Lahore, Pakistan \\ Prof. Dr. Syed Amir Gilani \\ Lahore School of Nursing \\ The University of Lahore \\ Lahore, Pakistan
}

\begin{abstract}
ABSTRECT
Introduction: Conflict is one of factors contributes to waste of energy and employees' capabilities. Since, instead of a proper combination of production elements with human resources and moving toward organization's objectives and effectiveness, they dissipate human and financial resources. On the other hand employee turnover is one of the most serious issues in current scenario. Educational growth, rapid technology and economical changes and cultural variations have influenced in all occupations..

Methods: Quantitative non-experimental co-relational research design was used to examine the relationship between conflict management style and turnover intention. In order to assess conflict management styles, data was collected through the standardized self-report questionnaire instrument developed by Johnson and Johnson in 2006. The instrument consists of thirty five proverbs. Each of the thirty-five proverbs corresponds to 1 of the 5 conflict management style (Withdrawing/avoiding, Forcing/competing, Smoothing/obliging, Compromising, and Confronting/integrating). It was used five-point scale: "Never do this" (1), "Seldom do this" (2), "Sometimes do this" (3), "Frequently do this" (4), "Usually do this" (5). The style with the highest score tends to be used the most frequently. The Anticipated Turnover Scale developed by Hinshaw and Atwood in 1984 to study turn over intention among nurses. It seeks to measure employs perception or opinion of the possibility of voluntarily terminating their present job.

Results: The findings of this study revealed that the nurses were most likely to prefer an obliging style of conflict management, followed in rank order by competing, compromising, confronting and avoiding, 43.2\% participants were in favor of intention to stay and 58.8 were in favor of intention to leave and there was statistically significant positive correlation between conflict management style and nurse's turnover intention and $p$ value is $\mathrm{p} \leq 0.01$.

Conclusions: Designing and implementing educational program on "different conflict management styles" and "how to manage work related conflict". Further research in this area is necessary with a larger sample ranging across different governmental and private hospitals in different governorates to enhance our understanding of the main causes of conflict and how to manage it.
\end{abstract}

Keywords- Conflict, Intention, Managers, Nurses, Styles, Turnover.

DOI: $10.7176 / \mathrm{JHMN} / 67-14$

Publication date:October $31^{\text {st }} 2019$

\section{INTRODUCTION}

Conflict is inevitable when individuals work together on a team or project. In a hospital setting, there are a large number of separate professions that need to work together to achieve the collective goal of patient health, safety, and well-being (Merrill \& Miller, 2015). 
Conflict is one of the most experienced issues by nurses and other healthcare team members. In fact, the Nursing Administration is also faced with challenges in resolving conflicts within the units of their nurses, outside their units, with other departments and even with the Hospital Administration. The roles of the nurses in each scenario and the kind of strategies they utilized also vary (Baddar, Salem, \& Villagracia, 2016).

Conflict has got enormous attention of researchers in the last few decades because it becomes global threat to every organization. It costs billions of dollars and results in intention of the employee to leave the organization (Alsam, Imran, Anwar, Hameed, \& Kafayat, 2013).

Employee turnover is one of the most serious issues in current scenario. Educational growth, rapid technology and economical changes and cultural variations have influenced in all occupations. Turnover of nurses is seen almost in all hospitals. High demand of the nurses and scarcity of the colleges offering nursing courses are the major issues to be considered. There are number of reasons for voluntary turnover of nurses such as poor leadership style, long working hours (Rajan, 2013).

Conflict is usually found in an individualistic culture, in which competition and individual achievement is stressed over interdependence (Craig \& Dunn, 2013).

A conflict model retrieved Ray 2011 publication was designed by two psychologists Kenneth Thomas and Ralph Kilmann. They defined that how individuals choose the conflict styles when they handle conflict. The model suggests five principles that guide individuals via the conflict process. These are competing, accommodating, avoiding, compromising, and collaborating Conflict management style (Ray, Chauhan, \& Lahiri, 2011).

Competing: is a win-lose approach, while every party tries to force its own interest. This strategy is only effective in emergency situations where time for discussion is limited and a prompt decision is needed. Accommodating: is a lose-win strategy. It is the opposite of competing. The individual neglects his/her own concerns for the other persons' satisfaction (Khosravi \& Esmaili, 2013).

Collaborating: is a win-win strategy. It is the opposite of avoiding. Each party shows respect to the ideas and values of the opposite side, in order to find a solution that satisfies both parties, although collaboration style is a time consuming process. it 'an integrated approach and a long-term resolution of conflict. Avoiding: is lose and lose approach in both opposite sides prefer to withdraw and leave conflict unresolved. Avoidance can be useful, when more information and analysis of the problem is needed or in case one party is more powerful. Compromising: is lose and lose orientation and each side has to give up a significant part of its interests. It can be chosen as a temporary resolution for a complicated issue (Marquis \& Huston, 2009).

In view of these effects, the present study is undertaken in the study area with a view of analyzing the effects of leadership strategies and turnover intention among nurses.

Registered nurses (RNs) suffer a higher turnover rate than any other industry. Registered nurse turnover was a widely-used measure to analyze the healthcare workforce (Kovner, Brewer, Fatehi, \& Jun, 2014). High registered nurse turnover was costly for the healthcare industry and affects the quality of care for all Americans (Cain, 2017).

An interpersonal conflict is a disagreement between two persons or subgroups of an organization involving significant bitterness and dissatisfaction. Health care professionals, who understand each other's roles and can work effectively together, have been shown to provide higher quality care and hence, to achieve desire out comes in patient care, it is essential to have good interpersonal relationship in terms of cooperation, collaboration, listen, and respect the values or positions of each other (Shah, 2017).

National Concept regarding conflict management strategies and turn over intention:

Conflict management strategies followed in Pakistan: A study conducted in Lahore Pakistan in 2016 and results revealed that the two sectors differed in the use of conflict management styles after controlling for the conflict types. Obliging, integrating, compromising and avoiding conflict management style were used more by doctors in public sector hospitals than those in private hospitals. However, none of the conflict types predicted conflict management styles and the pattern of prediction was similar for doctors working in private and public sector hospitals (Shazia Khalid \& Fatima, 2016).

Impact of conflict management style on nurses in Pakistan: A study conducted in Islam Abad Pakistan 2016 and it suggested that in Pakistan's corporate setup and what impact various conflict management styles have on dimensions of trust. Moderating effect of transformational leadership examined whether transformational leaders play their role in building trust. Results showed that integrating, obliging and compromising styles have a significant impact on cognitive trust. Whereas, dominating and avoiding were found to be having insignificant relationships with both trust dimensions. Integrating and compromising were the most preferred styles adopted by average number of respondents to manage their interpersonal conflicts at work (Javed, 2016).

Impact of conflict management style on organization in Pakistan: It is a significant issue within health care organizations all over the world. To overcome interpersonal conflict in the health care setting requires accurate 
knowledge and skills for health care professionals to reduce the occurrence of conflict. Learning to manage conflict may help nurses feel more job satisfaction and obviously have positive impacts on patient care. In addition, nurses are more concerns how they are treated. If they are treated with respect and dignity by colleagues, manager and are working with positive relationship and morale, they will experience a positive working environment with less conflict (Shah, 2017).

Turn over intention in Pakistan due to conflict: The work family conflict has a positive relationship with stress and turnover intentions that is if work family conflict increases the employees stress level, and the turnover intentions will also increase. The previous literature shows the relationship between work-family conflicts, stress and turnover intention. However, studies of work family conflicts in Asia are still in adequate particularly its rareness is observed in Pakistan (Khan et al., 2014).

\section{Globalize concept regarding conflict management strategies and turn over intention:}

Nurses turnover rate: For every $10 \%$ of nurses reporting job dissatisfaction, percentage of patients who recommend that hospital drops 2\% (Kutney-Lee et al., 2015). Surveys of newly licensed hospital-based nurses have shown that $43 \%$ leave their first jobs within 3 years of employment. The 1-year turnover rate among all newly licensed RNs was $17.5 \%$, and the 2-year turnover rate was $33.5 \%$. By geographic area, the 1-year turnover was lowest in the middle Atlantic region (13.7\%) and highest in the east south central region (25\%) (Kim \& Lee, 2016). Nurse's widespread job dissatisfaction, burnout, and frustration with health benefits signal problems for patient care. Employee turnover continues to be a challenge that contributes negatively to the U.S. economy (Zieba, 2016). In the United States, the cost to replace one employee is between $30 \%$ and $50 \%$ of the employee's annual salary, with total organizational expenditures as high as \$1 million (Eckhardt et al., 2013). In 2015, employers reported the average turnover rate was $6.4 \%$ (Holtom \& Burch, 2016). The cost of employee turnover in the workplace continues to be a difficult issue to prevent (Cain, 2017).

Nurse turnover, specifically, is a critical issue facing nurse managers (Sumaira Khalid, Rehman, \& Muqadas, 2018). Although turnover strategies reduce turnover and turnover costs (Park \& Shaw, 2013). few organizations have turnover strategies in place to prevent voluntary employee turnover (Rowlinson, Hassard, \& Decker, 2014). Organizational leaders should consider developing strategies to decrease voluntary employee turnover to keep an organization's most valuable asset the employee (Christens \& Inzeo, 2015).

RESEARCH QUESTION 1 - Which conflict management style mostly used among nurses in secondary care hospital?

RESEARCH QUESTION 2 - What are gender differences in using conflict management style?

RESEARCH QUESTION 3 - What is nurse's turnover intention among nurses in secondary care hospital?

RESEARCH QUESTION 4 - Is there any relationship between conflict management style and nurses turnover intention?

AIMS OF THE STUDY

The purpose of the study is to determine conflict management styles and nurses turn over intention in secondary care hospital Lahore SIGNIFICANCE OF THE STUDY

Patients: The finding may be help to control the turnover of nurses therefore they will get experience and be skill full in this scenario the quality of patient care may be improved.

Health Care Provider: Improved understanding of conflict management strategies. The results provided significant evidence to justify increased emphasis on nurse retention strategies and the creation of healthy work environments for nurses.

Organization: High rates of the turnover of nurses and chronic shortage of nurses are serious challenge for health care organization. On the Finding of the study the organization to know about employee's style of conflict management and its effects on nursing regarding turnover intention. Organization may arrange training session, workshop, and seminar to improve the strategies regarding conflict management in result turnover of nurses will be reduce/minimize the nurses' intention to leave. It will be suitable for the hospital management to take necessary steps to find the weak factors which produce turnover of nurses and take suitable remedial steps to control and prevent turnover of nurses and thereby improve the patients' satisfaction, nurses' satisfaction and reputation of the hospitals. The result cans also assist the organization to better understand how nurses work life and productivity affected by the conflict management strategies. Management can utilize the data from this study and can plan to educate and facilitate the employee which is best for taking good decision and minimize the turnover rate.

Policy Maker: This awareness will help the policy maker to design strategies and put into practice to improve the working environment for the nurses, improve their job satisfaction, and improve their performance. Accordingly, organization productivity and quality of care may be increased. 
Research Scholars: The result of this study will give direction to the future researcher to utilize this study as a literature and guidance. Additionally study will help them to identify the study gap. The findings of the study can be used as secondary data for future research scholars.

\section{LITERATURE REVIEW}

All organizations have differences in conflicts, conflict management style and its impact on the rate of turnover. Even the levels of turnover are found to be variable in area-to-area study. The areas, which have low unemployment rate and where it is easier for the people to get an alternate job, have highest rates of turnover. There are different factors that cause nurses turnover intention. Like sometimes, new job attracts employees and compel them to leave the previous one when conditions at present workplace does not match his/her family requirements .Another reason maybe the conflict management style. The below mention literature review support the study regarding the impact of conflict management style on nurses' turnover intention:

National researches on conflict management and nurses turn over intention:

Studies conducted in Pakistan regarding conflict management style mentioned below:

The impact of conflict management style on organization:

A study conducted in Lahore Pakistan 2016 and the finding of the study revealed that the impact of conflict management style on organization. $13.3 \%$ variance in obliging and $\mathrm{p}=.003 .16 .7 \%$ variance in integrating and $p=.003,9.6 \%$ variance in avoidance, $p=.164,11.4 \%$ variance in compromising, $p=.073$ and $12.3 \%$ variance $p=.044$ in dominating conflict management style. None of the conflicts types predicted obliging, integrating, avoiding, compromising and dominating conflict management style (Shazia Khalid \& Fatima, 2016).

In 2013 a study conducted in Sahiwal on the effects of conflict on organization and the results suggested that From this study we come to know about the effect of conflicts and there resolution in the organization there are no of factors that cause conflicts in the organization and destroying the organization stability and its culture This study is also beneficial to find out the best variables that can help to resolution of conflicts. The correlation matrix clearly indicates that by improving business environment, increasing motivation and taking care of employee perception we can able to minimize the conflicts (Mugal \& Khan, 2013).

The impact of conflict management style on nurses:

A study conducted in Islam Abad Pakistan 2016 on the impact of conflict management style on nurses' trust. The result revealed that the as shown in correlation table, cooperative conflict management styles i.e. integrating, obliging and compromising are positively and significantly related to both affective and cognitive dimensions of trust. Correlation value of integrating conflict management style with affective trust is $(\mathrm{R}=0.493)$. This means that integrating has $49.3 \%$ correlation with affective trust and $45.2 \%$ correlation with cognitive trust. Similarly, obliging style has significant and positive relationships with affective $p=.000$ and cognitive trust $p=.000$. Same goes for compromising style whose correlation value with affective trust is $p=.000$ and with cognitive trust is $\mathrm{p}=.000$ (Javed, 2016).

In Pakistan a study conducted in 2017 on impact of interpersonal conflict in health care setting on patient care; the role of nursing leadership style on resolving the conflict and this paper has implications for nurse leaders and organizations who seek to manage conflict among employees to reduce its negative consequences on working environment and organization productivity. Learning to manage conflict may help nurses feel more job satisfaction and obviously have positive impacts on patient care. In addition, nurses are more concerns how they are treated. If they are treated with respect and dignity by colleagues, manager and are working with positive relationship and morale, they will experience a positive working environment with less conflict (Shah, 2017).

The impact of conflict on nurses' turnover intention:

In 2016 a study conducted on turnover intention It has also been indicated that fostering a healthy working environment can ensure an encouragement for health care worker to remain under employment, The peaked correlation estimation is observed between workplace incivility and work burnout, rated at $\mathrm{P} \leq 0.01$, following to which is workplace incivility and turnover intentions estimated as $\mathrm{P} \leq 0.01$ ) and conclusively work burnout and turnover intentions valued at $\mathrm{P} \leq 0.05$ (Lu \& Gursoy, 2016).

International researches on relationship among conflict management and nurses turn over intention:

The numbers of researches conducted in different countries regarding conflict management style and nurses turnover intention. Some of them are mention bellow.

A study conducted in Saudi Arabia by Mohammed Alzahrani in 2013. In this study the author analyze the relationship between conflict management style and the turn over.

Integrating style: The result suggested that a statistically significant relationship existed between integrating style and propensity to leave the job. Compromising style: There is no positive correlation between integrating style and propensity to leave the job. The correlation was positive $(\mathrm{r}=.006)$. Obliging style: There is the correlation was positive $(\mathrm{r}=.006)$ not negative as the hypothesis predicted. Therefore, there is no negative correlation between obliging style and propensity to leave the job. Dominating style: there is correlation was positive $(r=.061)$ as the 
hypothesis predicted. However, $\mathrm{p}=.292>0.05$. The correlation between dominating style and propensity to leave the job is not significant. Avoiding style: there is correlation was positive $(\mathrm{r}=.061)$ as the hypothesis predicted. However, $\mathrm{p}=.192>0.05$. The correlation between avoiding style and propensity to leave the job is not significant (Alzahrani, 2013).

A study conducted in 2014 and published in world journal of medical sciences and result of this study was there were significant differences between the two hospitals regarding all conflict management styles and turnover intension except compromise style of conflict management and the p-value 0.000 . There is positive correlation between turnover intension and three conflict management styles including collaboration, compromise and avoiding and $p$-value $=.037, .002$ and .000 respectively. There was negative correlation between turnover intension and competing style and P-value $=000$. Also, the result suggested that no statistically significant negative correlation between turnover intension and accommodating P=599 (El Dahshan \& Keshk, 2014).

Choi investigated the conflict management in 2013 culture of 743 employees from bank branches located in Washington, DC and West Virginia. Three conflict management cultures were investigated. The respective cultures were dominant, collaborative, and avoidant conflict management culture. Results of this study revealed a positive correlation among collaborative in conflict management culture and job satisfaction (Choi, Ryter, \& Levine, 2013).

(Bradley, Klotz, Postlethwaite, \& Brown, 2013).

The authors of this study analyzed 116 studies on intra-group conflict and processes used to reduce intra group conflict. The conditions for the research articles were that each would measure conflict in relationships, tasks, and processes. Additionally, each article had to provide sufficient data with respect to effect sizes. Results of the study found that tasks conflicts were not disruptive in group outcomes; however, task conflict improved group performance (De Wit, Greer, \& Jehn, 2012).

A study conducted in 2015 and the result revealed that the correlation between organizational preference for avoiding conflict management style and intent to leave was not significant $(p>.01)$. The correlation between organizational preference for obliging and intent to leave was not significant $(\mathrm{p}>.01)$. The correlation between organizational preference for dominating and intent to leave was not significant $(\mathrm{p}>.01)$. The correlation between organizational preference for integrating and job satisfaction was negative and significant $(p=.004)$. The correlation between organizational preference for compromising and intent to leave was not significant $\mathrm{p}>.01$ (Springs, 2015).

A study conducted in 2014 regarding conflict management strategies and employee's productivity and the results revealed that there is significant relationship among collective bargaining and employee's productivity and the value of $p \leq 0.001$ and negotiation and employees productivity $p \leq 0.001$. The avoidance and imposing style was not significant $p \geq 0.05$ and $p \geq 0.05$ respectively. It will show that for improvement in productivity the bargaining and negotiation style is beneficial unlike imposing and avoidance style (Dawson, 2014).

\section{Gender differences in to choose conflict management strategies:}

The literature review shows that the relationship between gender to choose conflict management strategies and then conflict management strategies effects on nurses turn over intention.

In the light of previous researches it is noticed that males are more likely to use a dominating conflict management style than females. Females were much more likely to use an avoiding conflict management style which may limit the effectiveness of the team.

A recently study published in 2016 regarding conflict management style among principle of secondary school in Islamabad Pakistan. According to the results of study, it is clear that no one can avoid conflicts. Conflicts exist and every person tries to resolve the conflicts according to his/her abilities. Principals' personal characteristics and qualification is also one of the important factors to resolve the conflicts. There is slight difference in the use of conflict management strategies of rural and urban male/female principals (Kotaman, 2016).

A study conducted on influence of gender on conflict management style among employees of public banks in Ethiopia. The result shows that the gender was found significantly relate with compromising and integrating conflict management styles. On the contrary, gender was found no significant difference with avoiding, dominating and obliging conflict management styles. However, the results of the mean showed that men found to be more integrating, compromising, obliging, avoiding and dominating than females. The test shows that a statistically significant result has been found for compromising $\mathrm{p} \leq .05$ and integrating $\mathrm{p} \leq .05$ conflict management styles. Therefore, there is no difference in conflict management styles of compromising and integrating between male and female employees (Debas \& Narayana, 2016).

Other study conducted in 2013 at Nigeria there three generated hypotheses were tested using Pearson Product Moment Correlation and t-test statistical methods. The findings of the study revealed that: A significant relationship exists between gender difference and conflict management preference of the managers $\mathrm{P}<0.05$ ). It was also found that there was no significant difference between male and female managers' conflict management strategy preference $08 ; \mathrm{P}>0.05$. The finding reveals that there is no significant difference between female and 
male managers' conflict management efficiency on the basis of conflict management preference of the managers $\mathrm{P}>0.05$ (Akintayo \& Aje, 2015).

The authors conducted this study in 2014 and the study shows that males and females use different conflict management styles. There were significant differences between the two in terms of three of the five conflict management styles. The result shows that females were significantly more likely to use an avoiding and a compromising conflict management style. Males were significantly more likely to use a dominating conflict management style. Females were much more likely however to use an avoiding conflict management style which may limit the effectiveness of the team. When conflict is avoided, alternative ideas may not be considered.

\section{CONCEPTUAL FRAMEWORK}

Herzberg's present in 1968 two-factor theory, Vroom's present 1964 expectancy theory, and the dual concern conflict management theory Rahim, 2011 were used as theoretical foundations for this study. The combination of these theories have not been proffered as explanations for the relationship between job satisfaction and intent to leave based on organizational climate for a particular conflict management style practiced among peers in the workplace.

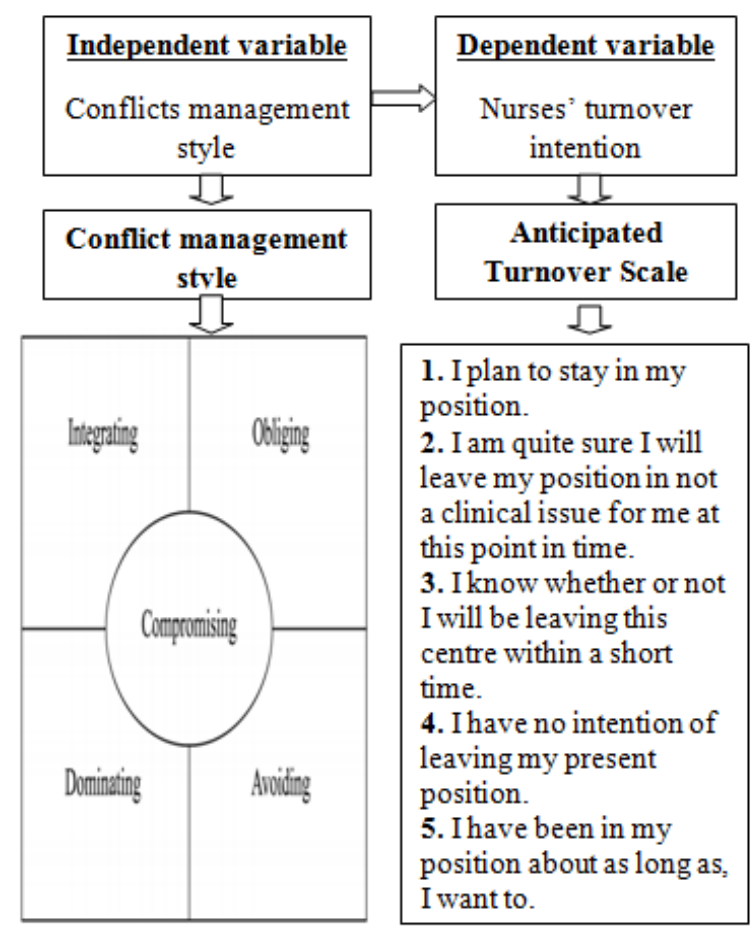

\section{METHODS}

\section{SETTING}

This study was conducted in wards (Emergency ward, OT, ICU, Gynae ward, Peads ward).

\section{RESEARCH DESIGN}

Quantitative non-experimental co-relational research design was used to examine the relationship between conflict management style and turnover intention.

\section{POPULATION}

The study population was 296 nurses, midwife and 14 head nurses and nursing supervisors working in this hospital. SAMPLING

Data was collected by convenient sampling technique from selected sample of 155 Registered Nurses, Head nurses, Nursing supervisors, Midwife. 


\section{RESEARCH INSTRUMENT}

Questionnaires were used to measure the variables in this study from both nurse managers and nurses' point of view it consists of three sections:

\section{Section-A: Demographic Data}

To collect the socio - demographic data (Such as age, gender, cadre, experience, qualification)

\section{Section-B: Conflict Management Style}

In order to assess conflict management styles, data was collected through the standardized self-report questionnaire instrument developed by Johnson and Johnson in 2006. The instrument consists of thirty five proverbs. Each of the thirty-five proverbs corresponds to 1 of the 5 conflict management style (Withdrawing/avoiding, Forcing/competing, Smoothing/obliging, Compromising, and Confronting/integrating). It was used five-point scale: "Never do this" (1), "Seldom do this" (2), "Sometimes do this" (3), "Frequently do this" (4), "Usually do this" (5). The style with the highest score tends to be used the most frequently.

Section-C: Turnover Intention: The Anticipated Turnover Scale developed by Hinshaw and Atwood in 1984 to study turn over intention among nurses. It seeks to measure employs perception or opinion of the possibility of voluntarily terminating their present job. The Anticipated turnover scale is a 12 items self administered instrument with a seven point likert scale ranging from agree strongly to disagree strongly.

\section{ANALYZE DATA}

The study was analyzing the data by SPSS version 16. Statistical analysis of the study was descriptive. The study sample was characterized by using a measure of central tendency (mean, median, and mode). The descriptive data was about demographic data which include age, gender, education independent variable was questionnaire regarding conflict management style and dependent variables were nurses' turnover intention. Pearson and ANOVA test was used to check the correlation between independent and dependent variable

\section{STUDY TIMELINE}

The Study duration was 4 months from January 2018 to May 2018.

\section{ETHICAL CONSIDERATION}

Written permission will be taken from the Ethical committee of LSN department in University of Lahore. Permission will be taken from the Nursing manager of Mian Shehbaz Sharif Hospital Lahore to conduct research study. All the participants will be informed about the purpose of the study. All information and collected data will be kept confidential by principal investigator hard copy in lock. Confidentiality of soft copy will be maintained by a coding. The subject will be informed that there are no disadvantages or risk on the procedures of the study.

\section{RESULTS}

This study is conducted at Mian Shehbaz Shrif hospital to determine the conflicts management style ant nurses' turnover intention. The result of this study distributed into two sections, first section is statistics of demographic factors, conflict management styles and anticipated turnover scale. Second section is relationship between demographic factors, independent and dependent tools named supervisory support scale.

\section{Demographic factors frequencies:}

Table 1.1 show that the frequency of demographics includes gender, age, experience, designation and qualification of the participants and the results were, both male and female participate in this study but frequency of male was $32(20.6 \%)$ low as compare to female nurses $123(79.4 \%)$. The age of participants was found minimum 23 to highest 37, participant's age group 23-27 years frequency was only $15(9.7 \%)$, majority $109(70.3 \%)$ participants were belong to age group 2832 years and moderately $31(20 \%)$ were fall in age group 33 - 37 years. Only $8(5.2 \%)$ participants have experience 1-4 years and 13- 16 years respectively majority of nurses $115(74.2 \%)$ have 5-8 years job experience and 24(15.5\%) have 23-27 years experience. Participants' designation as expected was only 14 $(9 \%)$ nursing supervisor, moderately $30(19.4 \%)$ registered midwife and majority $111(71.6 \%)$ registered nurses participate in the study. The qualification of the participants were found as $30(19.4 \%)$ diploma in midwife, majority $111(71.6 \%)$ diploma in general nursing, and only 14 (9.4\%) were hold a degree of bachelor sciences in nursing.

\section{Demographic factors frequencies}

Table 1.1

\begin{tabular}{llll}
\hline Demographic & Variable & Frequency & Valid Percent \\
\hline Gender: & Male & 32 & $20.6 \%$ \\
& Female & 123 & $79.4 \%$ \\
Age: & Total & 155 & $100 \%$ \\
& $23-27$ years & 15 & $9.7 \%$ \\
& $28-32$ years & 109 & $70.3 \%$ \\
& $33-37$ years & 31 & $20 \%$ \\
\hline
\end{tabular}




\begin{tabular}{llll}
\hline Designation: & $\begin{array}{l}\text { Registered midwife } \\
\text { Registered nurse } \\
\text { Nursing supervisor } \\
\text { Total }\end{array}$ & 30 & $111.4 \%$ \\
& & 14 & $71.6 \%$ \\
Qualification: & $\begin{array}{l}\text { Diploma } \\
\text { in midwife } \\
\text { Diploma.In general nursing } \\
\text { Post RN BSN }\end{array}$ & 111 & $10 \%$ \\
& 30 & $19.4 \%$ \\
\hline
\end{tabular}

Demographic factors, Median, Mode, Standard Deviation and Variance:

Table 1.2 shows the mean, median, mode, standard deviation and variance of demographic variable the highest mean 2.21 for experience, then 2.10 for age and 1.90 respectively for designation and qualification and the gender lowest mean was 1.79 . The variance was $(.165, .288, .373, .275, .275)$ were respectively for gender, age, experience, designation, qualification.

Table 1.2

Demographic factors, Median, Mode, Standard Deviation and Variance

\begin{tabular}{lccccc}
\hline \multicolumn{1}{c}{ Statistics } & Gender & Age & Experience & Designation & Qualification \\
\hline $\mathrm{N}$ & 155 & 155 & 155 & 155 & 155 \\
Mean & 1.79 & 2.10 & 2.21 & 1.90 & 1.90 \\
Median & 2.00 & 2.00 & 2.00 & 2.00 & 2.00 \\
Mode & 2 & 2 & 2 & 2 & 2 \\
Std. Deviation & .406 & .537 & .610 & .524 & .524 \\
Variance & .165 & .288 & .373 & .275 & .275 \\
\hline
\end{tabular}

Note: $\mathbf{N}=$ Population, STD=Standard

Conflict management style self assessment questionnaire frequencies:

Table 1.3 shows that the participant's response regarding the selection of conflict management style and results revealed that only $3(1.9 \%)$ participants use avoiding style of conflict management, moderately $51(34.8 \%)$ used forcing style and majority of participants $81(52.3 \%)$ working in mian Shehbaz Shrif secondary care hospital use obliging style of conflict management, 13 (8.4\%) use compromising and only 7 (4.5\%) use confronting while they are going to resolve conflicts.

\section{Conflict Management styles}

Table 1.3

\begin{tabular}{lcccc}
\hline Conflict Management style Frequency & Percent & Valid Percent & Cumulative Percent \\
\hline Avoiding & 3 & 1.9 & 1.9 & 1.9 \\
Forcing & 51 & 32.9 & 32.9 & 34.8 \\
Obliging & 81 & 52.3 & 52.3 & 87.1 \\
Compromising & 13 & 8.4 & 8.4 & 95.5 \\
Confronting & 7 & 4.5 & 4.5 & 100.0 \\
Total & 155 & 100.0 & 100.0 & \\
\hline
\end{tabular}




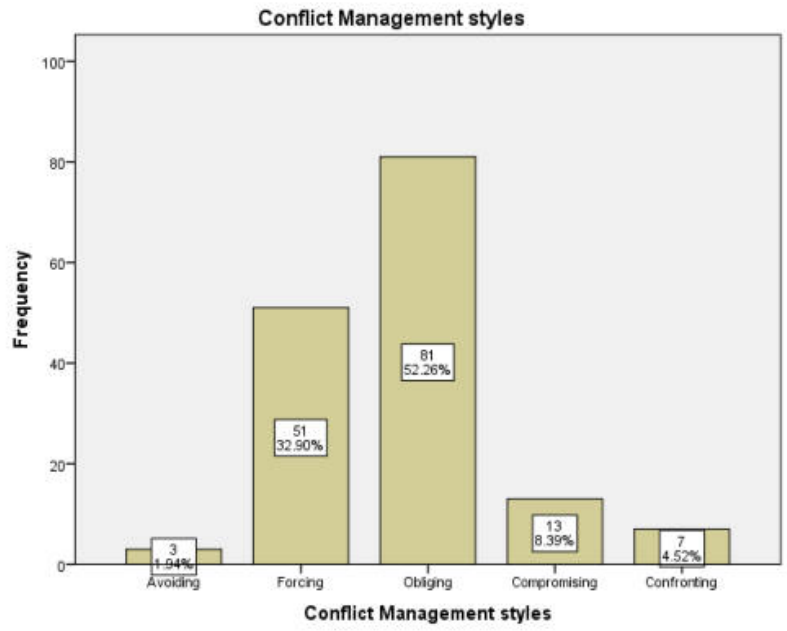

Anticipated turn over scale frequencies:

Figure 1.1

Table 1.4 shows that the participants response regarding anticipated turnover scale and reults revealed that 67 (43.2\%) participats respond in the favour of intention to stay and majority $88(56.8 \%)$ respond in the favour of intention to stay.

Anticipated Turnover scale

Table 1.4

\begin{tabular}{ccccc}
\hline Anticipated Turnover Scale Frequency & Percent & Valid Percent & Cumulative Percent \\
\hline Intention to stay & 67 & 43.2 & 43.2 & 43.2 \\
intention to leave & 88 & 56.8 & 56.8 & 100.0 \\
Total & 155 & 100.0 & 100.0 & \\
\hline
\end{tabular}

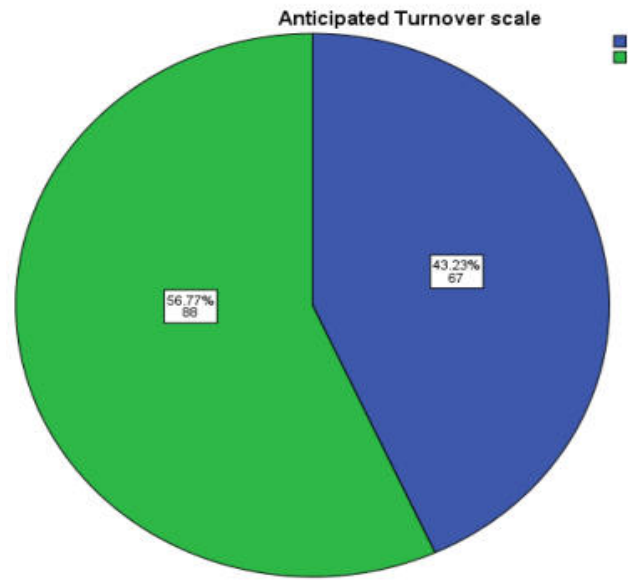

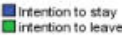

Figure 1.2

\section{Amticipated turnover scale statistics}

Table 1.5 shows that the mean, median, mode, standard deviation and varience of participants regarding turnover intention. the highest mean value 5.52 of item five that was "If I got another job after tommorow, I would give it serious considration" and the lowest is 2.78 for item two that was "I am quite sure I will leave my position in not a clinical issue for me at this point in time.

\section{Amticipated turnover scale}


Table 1.5

\begin{tabular}{|c|c|c|c|c|c|c|}
\hline Sr.no & Items Of The Scale & Mean & Median & Mode & $\begin{array}{c}\text { Std. } \\
\text { Deviation }\end{array}$ & Variance \\
\hline 1 & I plan to stay my position. & 4.68 & 5.00 & 5 & 1.450 & 2.103 \\
\hline 2 & $\begin{array}{l}\text { I am quite sure I will leave my position in not } \\
\text { a clinical issue for me at this point in time. }\end{array}$ & 2.78 & 300 & 3 & 1.224 & 1.497 \\
\hline 3 & $\begin{array}{l}\text { Deciding to stay or leave my position is not } \\
\text { critical issue for me at this point in time }\end{array}$ & 5.24 & 5.00 & 5 & 1.325 & 1.754 \\
\hline 4 & $\begin{array}{l}\text { I know whether or not I will be leaving this } \\
\text { centre within a short time. }\end{array}$ & 5.19 & 5.00 & 5 & 1.270 & 1.612 \\
\hline 5 & $\begin{array}{l}\text { If I got another job after tommorow, I would } \\
\text { give it serious considration. }\end{array}$ & 5.52 & 5.00 & 5 & 1.095 & 1.199 \\
\hline 6 & $\begin{array}{l}\text { I have no intention of leaving my present } \\
\text { position. }\end{array}$ & 3.30 & 3.00 & 4 & 1.513 & 2.288 \\
\hline 7 & $\begin{array}{l}\text { I have been in my position about as long as, I } \\
\text { want to. }\end{array}$ & 4.41 & 4.00 & 3 & 1.595 & 2.543 \\
\hline 8 & I am certain I will be staying here. & 5.41 & 5.00 & 5 & 1.073 & 1.152 \\
\hline 9 & $\begin{array}{l}\text { I don't have any specific idea how much } \\
\text { longer I will stay. }\end{array}$ & 2.92 & 2.00 & 2 & 1.655 & 2.740 \\
\hline 10 & I plan to hang on to this job. & 3.55 & 4.00 & 4 & 1.305 & 1.703 \\
\hline 11 & $\begin{array}{l}\text { There are big doubts in my mind as to } \\
\text { whether or not I will really stay in this centre }\end{array}$ & 3.75 & 4.00 & 5 & 1.311 & 1.719 \\
\hline 12 & I plan to leave this position shortly & 3.08 & 3.00 & 3 & 1.314 & 1.727 \\
\hline
\end{tabular}

Note: Disagree Strongly=1, Moreratly Disagree=2, Slightly Disagree=3, Uncertain=4, Slightly Agree=5, Moreratly Agree=6, Agree Strongly=7.

Normality of data regarding conflict management style

Table 1.6 shows that the significance of data normality and $\mathrm{p}=.200$ for Kolmogorov-Smirnov and $\mathrm{p}=.539$ for Shapiro-Wilk.

\begin{tabular}{lrrrrrr} 
& \multicolumn{5}{c}{ Tests of Normality } \\
Table 1.6 \\
\hline & \multicolumn{5}{c}{ Kolmogorov-Smirnov } \\
\cline { 2 - 7 } Conflict Management Style & Statistic & df & Sig. & Statistic & df & Sig. \\
\cline { 2 - 7 } & .154 & 154 & .200 & .914 & 154 & .539 \\
\hline
\end{tabular}

a. Lilliefors Significance Correction 


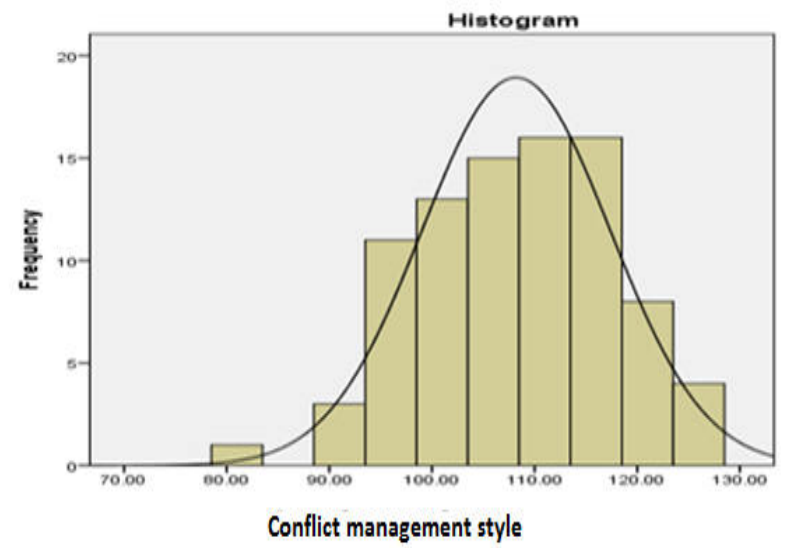

Normality of data of anticipated turnover scale

Figure 1.3

Table 1.7 shows that the significance of data normality and $p=.029$ for Kolmogorov-Smirnov and $p=.209$ for Shapiro-Wilk.

\section{Tests of Normality}

Table 1.7

\begin{tabular}{lcccccc}
\hline & \multicolumn{3}{c}{ Kolmogorov-Smirnov } & \multicolumn{3}{c}{ Shapiro-Wilk } \\
\cline { 2 - 7 } & Statistic & Df & Sig. & Statistic & df & Sig. \\
Anticipated Turnover Scale & .076 & 155 & .029 & .988 & 155 & .209 \\
\hline
\end{tabular}

a. Lilliefors Significance Correction

Histogram

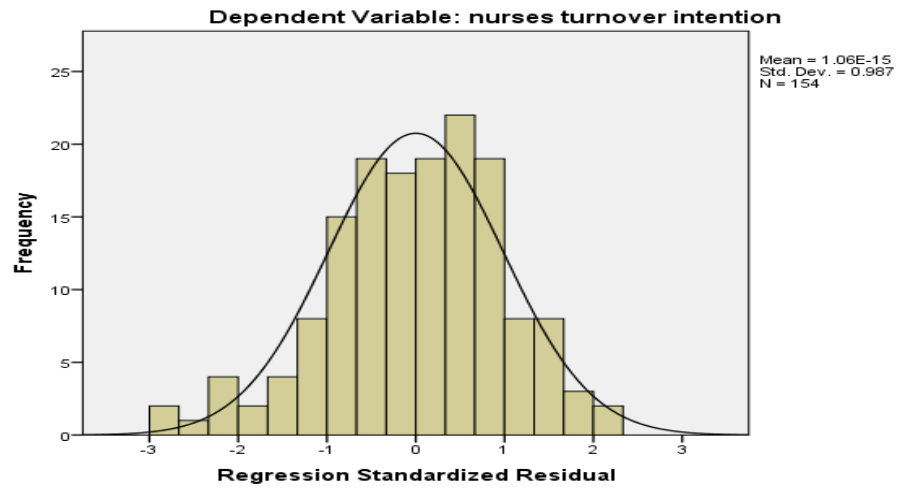

Normal Q-Q Plot of Anticipated turn over scale

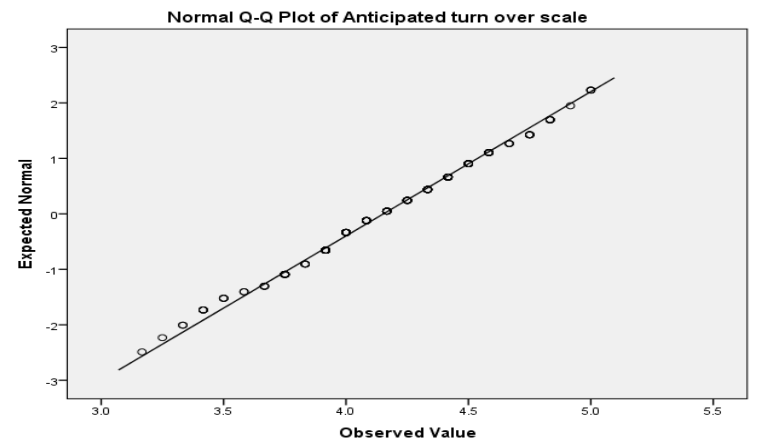

Figure 1.5

Gender Deference regarding the selection of conflict management style:

Table 1.8 shows that the gender deference's in selection of conflict management style and results revealed that the total male participants were 32 and female participants were 123 and further analysis revealed that the female choose avoiding style of conflict management more than male, and male use forcing style of conflict management more than female. On the other hand it is estimated that female used obliging, compromising, and integrating style of conflict management more than male. 


\section{Gender Deference regarding the selection of conflict management style}

Table 1.8

\begin{tabular}{|c|c|c|c|c|}
\hline \multirow[t]{2}{*}{ Conflict Management Style } & $\begin{array}{r}\text { Male } \\
\mathbf{N}=32\end{array}$ & & $\begin{array}{r}\text { Female } \\
N=123\end{array}$ & \multirow[b]{2}{*}{ Percentage } \\
\hline & Frequency & Percentage & Frequency & \\
\hline Avoiding & 0 & $0 \%$ & 3 & $2.4 \%$ \\
\hline Forcing & 16 & $50 \%$ & 38 & $30.8 \%$ \\
\hline Obliging & 12 & $37.6 \%$ & 69 & $56.09 \%$ \\
\hline Compromising & 3 & $9.3 \%$ & 7 & $5.69 \%$ \\
\hline Integrating & 1 & $3.1 \%$ & 6 & $4.87 \%$ \\
\hline Total & 32 & $100 \%$ & 123 & $100 \%$ \\
\hline
\end{tabular}

Note: $\mathbf{N}=$ Population

Relationship between conflict management style and nurses turn over intention

Correlation:

Table 1.9 shows that the mean value 91.5714 for conflict management style and 4.1527 for nurses turnover intention.

Table 1.9

\section{Correlation}

\begin{tabular}{lccc}
\hline & Mean & Std. Deviation & $\mathrm{N}$ \\
\hline Conflict Management Style & 91.5714 & 5.50799 & 154 \\
Nurses Turnover Intention & 4.1527 & .38445 & 155 \\
\hline
\end{tabular}

Note: Std= standard deviation, $\mathbf{N}=$ Population

Table 1.10 shows that the correlation of conflict management style and nurses turnover intention and $\mathrm{p}$ value is $\mathrm{p}=.011$, so it is estimated that there was significant co-relation between conflict management style and nurses turnover intention.

\begin{tabular}{|c|c|c|c|}
\hline \multicolumn{4}{|c|}{$\begin{array}{c}\text { Correlations } \\
\text { Table } 1.10\end{array}$} \\
\hline & & Conflict Management Style & $\begin{array}{l}\text { Nurses Turnover } \\
\text { Intention }\end{array}$ \\
\hline \multirow{3}{*}{ conflict management style } & Pearson Correlation & 1 & $-.277^{* *}$ \\
\hline & Sig. (2-tailed) & & .011 \\
\hline & $\mathrm{N}$ & 154 & 154 \\
\hline \multirow{3}{*}{ nurses turnover intention } & Pearson Correlation & $-.277^{* *}$ & 1 \\
\hline & Sig. (2-tailed) & .011 & \\
\hline & $\mathrm{N}$ & 154 & 155 \\
\hline
\end{tabular}

Note: $* *$. Correlation is significant at the 0.01 level (2-tailed).

Table 1.11 shows that $R$ value and error of the estimate.

Model Summary

Table 1.11

\begin{tabular}{ccccc}
\hline Model & $\mathrm{R}$ & R Square & Adjusted R Square & Std. Error of the Estimate \\
\hline 1 & $.371^{\mathrm{a}}$ & .137 & .114 & .36282 \\
\hline
\end{tabular}

Note: a. Predictors: (Constant), Qualification of the participant, Experience of the participant, conflict management style, Age of the participant.

b. Dependent Variable: nurses turnover intention

Table 1.12 shows that the relationship of conflict management styles, demographic factors with nurse's turnover intention and $\mathrm{p}$ value for relationship conflict management style and nurses turnover intention is .000 of Age and nurses turnover intention is $\mathrm{p}=.002$, experience and nurses turnover intention $\mathrm{p}=.185$, qualification and nurses turnover intention. 32

Coefficients $^{\mathrm{a}}$

Table 1.12

\begin{tabular}{ccccccc}
\hline & Model & \multicolumn{2}{c}{ Unstandardized Coefficients } & Standardized Coefficients & t & Sig. \\
\cline { 3 - 5 } & & $\mathrm{B}$ & Std. Error & Beta & & \\
(Constant) & 6.362 & .537 & & 11.850 & .000 \\
1 & conflict management style & -.018 & .006 & -.253 & -3.142 & .002 \\
& Age of the participant & -.096 & .072 & -.133 & -1.332 & .185
\end{tabular}




\begin{tabular}{cccccc}
\hline Experience of the participant & -.060 & .061 & -.096 & -.985 & .326 \\
Qualification of the participant & -.135 & .062 & -.181 & -2.159 & .032 \\
\hline
\end{tabular}

a. Dependent Variable: Nurses Turnover Intention

\section{DISCUSSION}

Healthcare sectors constitute complex work on the suggestion of the staff nurses because they place, where healthcare team coming from reported their issue in their nursing services in which involved nurse managers, head nurses and nursing supervisors. Then it is depends upon how individual manage the conflict. This study conducted in secondary care hospital among nurse to identify that how nurses mange the conflict and as well as what is the relationship between conflict management style and nurses turnover intention. Study revealed that there is significant relationship among conflict management style and nurses turnover intention.

Model developed by Rahim was utilized as theoretical framework. Rahim defined conflict as interactive state manifested in compatibility, disagreement, or difference within or between social entities, Rahim asserted that modern organizations need conflict management not conflict resolution. Conflict management styles refer to individual's distinctive ways of handling conflict in any interaction incidents. Conflict management strategies enable organizations to exclude the negative consequences of destructive conflict and turn conflict into a positive force and a learning opportunity for organizations. Rahim asserts that conflict management strategies should be designed to enhanced organizational learning and effectiveness, and also satisfy the needs and expectations of all participants (Rahim et al., 2011).

In related studies it was discovered that conflict management style is easy to talk but difficult to practice. The result of the study was approximately similar to study conducted in 2013 by Lampros Spyridon on conflict management style and the gender (Spyridon, 2013) and other study conducted in 2001 regarding gender and conflict management style suggested that there is no difference among gender in two conflict management styles involved avoiding and compromising (Valentine, 2001).

Related studies conducted in government tertiary hospital in the Kingdom of Saudi Arabia published in 2016 (Baddar et al., 2016) and the results were very closed to the current study.

Another study conducted in 2014 in Jordon (Al-Hamdan, Norrie, \& Anthony, 2014), in 2011 in Oman (AlHamdan, Shukri, \& Anthony, 2011), and in 2015 a study conducted in Egypt (Hashish, Hamouda, \& Taha, 2015), another study conducted in 1991 (Cavanagh, 1991) regarding conflict management styles and the results were deferent because it suggested that in the majority of nurses used integrating style of conflict management but the current study revealed that the majority of nurses both male and female used obliging style of conflict management

A study conducted in 2014 regarding conflict management style and its effects on nurse's turnover intention. The current study revealed that half of the studied conflict. In the same context, this finding was consistent nurses had nursing school diploma and (78.9\%) were with Kanani and Farahani who ranked conflict female. This results were in the same line with management styles as following avoidance followed by Mosa deghrad who found three fourth of the compromise followed by accommodation followed by participants were females $(72.6 \%)$ and the majority of collaboration and lastly competition . studied sample had bachelors' degree (61.9\%).

\section{Limitations:}

This study found many limitations;

$>$ Time duration was too short.

$>$ The study design is convenient sample technique.

$>$ Likert scale questionnaire has been used in this study.

$>$ Data collection was faced lot of issues.

$>$ The respondents of the study have very careless attitude regarding filling questionnaire.

$>$ Participants of study have no idea about the importance of the filling questionnaire.

\section{Conclusion:}

Data was collected only one hospital.

Despite the limitations of this study, the findings from the current study contributed to our understanding of relationship between conflicts management style and turnover intension among nurses. The main conclusion of 
this research was that the most used conflict management style was avoiding followed by collaborating and lastly competing style. The finding from this study revealed that there was statistically significant positive correlation between turnover intension and the three conflict management styles (collaboration, compromise and voiding) while, there was statistically significant negative correlation between turnover intension and competing style.

\section{Recommendation:}

In the light of the study findings, the following are recommended:

Designing and implementing educational program on different conflict management styles" and "how to manage work related conflict". Future research in this area is necessary with a larger sample ranging across different governmental and private hospitals in different governorates to enhance our understanding of the main causes of conflict and to investigate its correlation with turnover intention among nurses and as well as it is necessary to assess the other factors which enhance turnover intention.

\section{ACKNOWLEDGEMENT}

This research was biggest step for me and that was not possible without the guidance and enlightenment blessed by God. So I thank to God for the blessings.

I would like to thank my research supervisor Mr. Muhammad Hussain for his support and guidance throughout the course of this research study and for providing an excellent role model for a novice researcher.

I would like to thanks Ms. Chanda Jabeen, being a lecturer she teach the basics of research by her excellent teaching strategies.

I would like to thanks authorities of university who gave me permission to collect data from the community. I am also thankful to the participants who actively participated, and gave me their precious time and information in this research.

I would also thanks to my mother, wife, sisters and my cute son Jason who stood by me and bear my not attending to them in busy days of my research study.

Last but not least, I am very thankful to Mr. Muhammad Sabir who being teacher of English subject supports me and correction without any benefit. This research was biggest step for me and that was not possible without the guidance and enlightenment blessed by God. So I thank to God for the blessings.

I would like to thank my research supervisor Mr., M. Hussain for his support and guidance throughout the course of this research study and for providing an excellent role model for a novice researcher.

I would like to thanks Mr. Muhammad Afzal being a subject teacher he teach the basics of research by her excellent teaching strategies.

I would like to take this opportunity to thank institutional review board at university of Lahore for approving my project.

I am also thankful to the participants who actively participated, and gave me their precious time and information in this research.

Last but not least, I am very thankful to Mr. Muhammad Sabir who being teacher of English subject supports me and correction without any benefit.

\section{Dedication}

I would like to dedicate this project to my parents who inspired me to become a nurse and motivated me further to advance my degree. I would like to dedicate the success of this two years long journey to my wife Samreen, my children Jayson and Roman and my mother Vilot. Their continued love, support, and inspiration were essential to the successful accomplishment of this journey. I would also thanks to them who stood by me and bear my not attending to them in busy days of my research study. I need to thanks and dedicate to the most important friend in my life, Ms Hina Samuel, who has been a continuous source of motivation. Unreservedly and whose good examples have educated me to work hard for the things that I desire to complete.

\section{References:}

Abiodun, A. R. (2014). Organizational conflicts: causes, effects and remedies. International Journal of Academic Research in Economics and Management Sciences, 3(6), 118.

Afzalur Rahim, M. (2002). Toward a theory of managing organizational conflict. International journal of conflict management, 13(3), 206-235.

Akintayo, D., \& Aje, C. (2015). Gender Difference and Conflict Management Strategy Preference among Managers in Public Organizations in South-Western Nigeria. World Academy of Science, Engineering and Technology, International Journal of Economics and Management Engineering, 2(11).

Al-Hamdan, Z., Norrie, P., \& Anthony, D. (2014). Conflict management styles used by nurses in Jordan. Journal of Research in Nursing, 19(1), 40-53. 
Al-Hamdan, Z., Shukri, R., \& Anthony, D. (2011). Conflict management styles used by nurse managers in the Sultanate of Oman. Journal of clinical nursing, 20(3-4), 571-580.

Alsam, N., Imran, R., Anwar, M., Hameed, Z., \& Kafayat, A. (2013). The Impact of Work Family Conflict on Turnover Intentions: Empirical Evidence from Pakistan. World Applied Sciences Journal, 24(5), 628633.

Alzahrani, M. (2013). A Comparative Study of the Relationships Between Conflict Management Styles and Job Satisfaction, Organizational Commitment, and Propensity to Leave the Job Among Saudi and American Universities' Faculty Members. Florida Atlantic University.

Baddar, F., Salem, O. A., \& Villagracia, H. N. (2016). Conflict resolution strategies of nurses in a selected government tertiary hospital in the Kingdom of Saudi Arabia. Journal of Nursing Education and Practice, $6(5), 91$.

Cain, Q. E. (2017). Strategies for Reducing Registered Nurse Voluntary Turnover. Walden University.

Cavanagh, S. J. (1991). The conflict management style of staff nurses and nurse managers. Journal of advanced nursing, 16(10), 1254-1260.

Choi, A. M., Ryter, S. W., \& Levine, B. (2013). Autophagy in human health and disease. New England Journal of Medicine, 368(7), 651-662.

Christens, B. D., \& Inzeo, P. T. (2015). Widening the view: situating collective impact among frameworks for community-led change. Community Development, 46(4), 420-435.

Craig, G. J., \& Dunn, W. L. (2013). Understanding human development: Pearson Higher Ed.

Dawson, T. L. (2014). The influence of supportive nursing leadership in staff nurse retention.

De Wit, F. R., Greer, L. L., \& Jehn, K. A. (2012). The paradox of intragroup conflict: a meta-analysis. Journal of applied psychology, 97(2), 360.

Debas, A., \& Narayana, E. (2016). The Influence of Gender on Conflict Management Styles: A Study among Employees of Public Banks in Ethiopia. International Journal of Science and Research, 577-582.

Eckhardt, S., Brunetto, P. S., Gagnon, J., Priebe, M., Giese, B., \& Fromm, K. M. (2013). Nanobio silver: its interactions with peptides and bacteria, and its uses in medicine. Chemical reviews, 113(7), 4708-4754.

El Dahshan, M. E. A., \& Keshk, L. I. (2014). Managers' conflict management styles and its effect on staff nurses' turnover intention at Shebin El Kom Hospitals, Menoufiya Governorate. World J Med Sci, 11(1), 132143.

Hashish, E. A. A., Hamouda, G. M., \& Taha, E. E.-S. (2015). Nursing Students' Perception of Conflict Management Styles of Their Nursing Educators. Journal of Education and Practice, 6(21), 21-30.

Hinshaw, A. S., \& Atwood, J. R. (1984). Nursing staff turnover, stress, and satisfaction: models, measures, and management Annual review of nursing research (pp. 133-153): Springer.

Holtom, B. C., \& Burch, T. C. (2016). A model of turnover-based disruption in customer services. Human Resource Management Review, 26(1), 25-36.

Javed, S. (2016). Impact of Conflict Management Styles on Affective and Cognitive Trust Moderating Role of Transformational Leadership.

Kaelicke, E., Ambruoso, N., Bannert, M., Bellis, G., Bhatt, C. V., Crowe, G., . . Giesche, G. (2010). Development processes representation and management: Google Patents.

Khalid, S., \& Fatima, I. (2016). CONFLICT TYPES AND CONFLICT MANAGEMENT STYLES IN PUBLIC AND PRIVATE HOSPITALS. Pakistan Armed Forces Medical Journal(1), 122.

Khalid, S., Rehman, C. A., \& Muqadas, F. (2018). EXPLORING THE MEDIATING ROLE OF AFFECTIVE COMMITMENT ON ORGANIZATIONAL JUSTICE AND TURNOVER INTENTION. Pakistan Business Review, 19(4), 1012-1028.

Khan, M., Nazir, N., Kazmi, S., Khalid, A., Kiyani, T., \& Shahzad, A. (2014). Work-family conflict and turnover intentions: mediating effect of stress. International Journal of Humanities and Social Science, 4(5), 92100.

Khosravi, M., \& Esmaili, M. (2013). Studying the Relationship between Knowledge Management and Organizational Entrepreneurship (Case Study: Labor and Social Affairs Department of Qom). Journal of Basic and Applied Scientific Research, 3(7), 643-650.

Kim, S., \& Lee, K. (2016). Predictors of turnover among new nurses using multilevel survival analysis. Journal of Korean Academy of Nursing, 46(5), 733-743.

Kotaman, H. (2016). Turkish prospective early childhood teachers' emotional intelligence level and its relationship to their parents' parenting styles. Teacher Development, 20(1), 106-122.

Kovner, C. T., Brewer, C. S., Fatehi, F., \& Jun, J. (2014). What does nurse turnover rate mean and what is the rate? Policy, Politics, \& Nursing Practice, 15(3-4), 64-71.

Kutney-Lee, A., Stimpfel, A. W., Sloane, D. M., Cimiotti, J. P., Quinn, L. W., \& Aiken, L. H. (2015). Changes in patient and nurse outcomes associated with magnet hospital recognition. Medical care, 53(6), 550. 
Lu, A. C. C., \& Gursoy, D. (2016). Impact of job burnout on satisfaction and turnover intention: Do generational differences matter? Journal of Hospitality \& Tourism Research, 40(2), 210-235.

Marquis, B. L., \& Huston, C. J. (2009). Leadership roles and management functions in nursing: Theory and application: Lippincott Williams \& Wilkins.

Merrill, L., \& Miller, K. (2015). Interprofessional conflict management study in a hospital setting.

Mugal, M., \& Khan, M. (2013). Impact of conflict and conflict management on organizational performance. International Journal of Modern Business-Issues on Global Market, 1(3), 1-19.

Park, T.-Y., \& Shaw, J. D. (2013). Turnover rates and organizational performance: A meta-analysis. Journal of applied psychology, 98(2), 268.

Rahim, N. A., Chaniago, K., \& Selvaraj, J. (2011). Single-phase seven-level grid-connected inverter for photovoltaic system. IEEE transactions on industrial electronics, 58(6), 2435-2443.

Rajan, D. (2013). Impact of nurses turnover on organization performance. Afro Asian Journal of Social Sciences, 4(4), 1-18.

Ray, B., Chauhan, N. B., \& Lahiri, D. K. (2011). Oxidative insults to neurons and synapse are prevented by aged garlic extract and S-allyl-1-cysteine treatment in the neuronal culture and APP-Tg mouse model. Journal of neurochemistry, 117(3), 388-402.

Rowlinson, M., Hassard, J., \& Decker, S. (2014). Research strategies for organizational history: A dialogue between historical theory and organization theory. Academy of Management Review, 39(3), 250-274.

Rumelili, B., \& Todd, J. (2018). Paradoxes of identity change: Integrating macro, meso, and micro research on identity in conflict processes. Politics, 38(1), 3-18.

Schyns, B., \& Schilling, J. (2013). How bad are the effects of bad leaders? A meta-analysis of destructive leadership and its outcomes. The Leadership Quarterly, 24(1), 138-158.

Shah, M. (2017). Impact of Interpersonal Conflict in Health Care Setting on Patient Care; the Role of Nursing Leadership Style on Resolving the Conflict. Nurse Care Open Acces J, 2(2), 00031.

Springs, M. J. (2015). Examining Organizational Conflict Management Style Climate: Moderator of Job Satisfaction and Intent to Leave a Management Consulting Organization: Northcentral University.

Spyridon, L. I. (2013). Conflict management styles and the gender.

Valentine, P. E. (2001). A gender perspective on conflict management strategies of nurses. Journal of Nursing Scholarship, 33(1), 69-74.

Zieba, M. (2016). Knowledge Safety in small and medium-Size Service Companies: Case Study Analysis. Paper presented at the European Conference on Knowledge Management. 